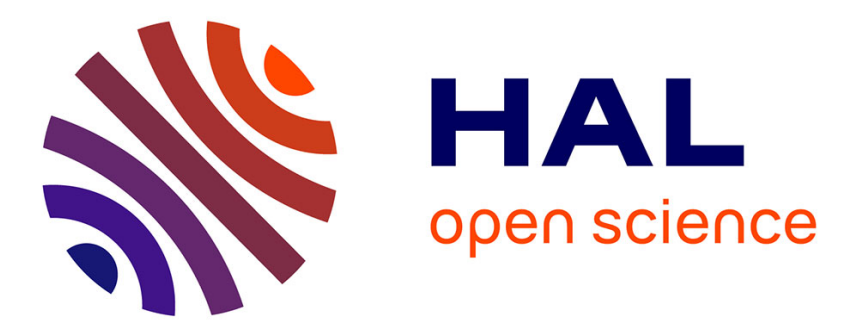

\title{
A generic method to model carbon emission of combined cycle for environmental power dispatch
}

Remy Rigo-Mariani, Keck Voon, Jan Maciejowski, Keck Voon Ling

\section{To cite this version:}

Remy Rigo-Mariani, Keck Voon, Jan Maciejowski, Keck Voon Ling. A generic method to model carbon emission of combined cycle for environmental power dispatch. 2017 Asian Conference on Energy, Power and Transportation Electrification (ACEPT), Oct 2017, Singapore, France. pp.1-6, 10.1109/ACEPT.2017.8168578 . hal-03520032

\section{HAL Id: hal-03520032 \\ https://hal.science/hal-03520032}

Submitted on 10 Jan 2022

HAL is a multi-disciplinary open access archive for the deposit and dissemination of scientific research documents, whether they are published or not. The documents may come from teaching and research institutions in France or abroad, or from public or private research centers.
L'archive ouverte pluridisciplinaire HAL, est destinée au dépôt et à la diffusion de documents scientifiques de niveau recherche, publiés ou non, émanant des établissements d'enseignement et de recherche français ou étrangers, des laboratoires publics ou privés. 


\title{
A Generic Method to Model Carbon Emission of Combined Cycle for Environmental Power Dispatch
}

\author{
Remy Rigo-Mariani ${ }^{1}$, Keck Voon Ling $^{2}$, Jan Maciejowski ${ }^{3}$ \\ 1 - Cambridge Centre for Advanced Research and Education in Singapore Ltd, 1 CREATE Way, Singapore \\ 2 - School of Electrical and Electronic Engineering Nanyang Technological University, 50 Nanyang Ave, Singapore \\ 3 - Department of Engineering, University of Cambridge, Cambridge CB2 1PZ, UK, and ERI@N, NTU, Singapore \\ remyrm@ntu.edu.sg,EKVLING@ntu.edu.sg,jmm@eng.cam.ac.uk
}

\begin{abstract}
This paper proposes a generic methodology for combined cycle gas turbines (CCGT) modeling. The main objectives are the estimation of the $\mathrm{CO}_{2}$ emissions for specific units and their integration in an environmental power dispatch that considers several plants. At first a design procedure aims at calibrating the model using the sparse information advised by the manufactures. Off-design points are also investigated in order to estimate the $\mathrm{CO}_{2}$ emissions on the whole operating range of the units. The obtained results show a good consistency with the emission coefficients found in the literature for that type of units. Then those carbon costs are used as input parameters for a unit commitment problem (UC). The Mixed Integer Linear Programming (MILP) formulation minimizes the global emissions for a set of different units on Jurong Island in Singapore. The grid emission factor finally obtained for the simulated network displays values close to the registered field data which validates the developed model.
\end{abstract}

Keywords - combined cycle gas turbine, design, $\mathrm{CO}_{2}$ emissions, environmental unit commitment, power dispatch, optimization

\section{INTRODUCTION}

The work presented in this paper has been led in the framework of a wider study whose objective is to simulate the operation of the Jurong Island power grid in Singapore. The island has four thermal power plants with thirteen identified combined cycle gas turbines (CCGT) [1]. The first concern is to model the power generation on site to perform a power dispatch that minimizes the amount of $\mathrm{CO}_{2}$ generated. Such unit commitment (UC) problems have been widely studied in the literature. The traditional objective is to minimize the generation cost while meeting the load and fulfilling system operating constraints [2]. Here the objective only refers to the minimization of the $\mathrm{CO}_{2}$ emissions. Most of the time those emissions are added to the objective function as a linear cost with the generated power as in [3]. Another alternative consists in considering a quadratic curve for the $\mathrm{CO}_{2}$ emissions - the same way it is commonly done for the generation cost - as well as $\mathrm{CO}_{2}$ start-up costs [4]. Then either a bi-objective (cost/ $\left.\mathrm{CO}_{2}\right)$ optimization is performed or the $\mathrm{CO}_{2}$ is simply added to the conventional objective function while introducing carbon penalties [2]. Cubic functions can also be found in the literature [5] as well as exponential formula when other types of pollutant are considered [6]. In addition to that variety of cost models, their attached coefficients are rarely justified. They

The authors acknowledge the support by the Singapore National Research Foundation under its Campus for Research Excellence And Technological Enterprise (CREATE) programme and the Cambridge Centre for Advanced Research in Energy Efficiency in Singapore Ltd (CARES). come from pre-established test cases and can display wide ranges of values even for the same type of unit. Indeed, a great part of such power systems studies mainly focus on validating the problem formulation and the algorithms used to solve them. In order to accurately model those emissions for thermal units one must pay attention to energy conversion aspects and model calibration. CCGT has received extensive attention, since it offers enhanced performances compared to conventional gas turbines (GT). An increasing number of heavy duty units has been installed in electrical systems across the world in recent decades to replace conventional coal/oil power plants [7]. Most CCGT studies are concerned with optimal design that minimizes the cost for the plant owner as in [8]. However, their performance dramatically decreases when deviating from their nominal operating point. Thus off-design operations have to be considered carefully, especially when a power dispatch will require the system to work on its whole operating range [9]. The main motivation of the present study is then to use a CCGT model in order to get realistic coefficients for carbon emissions in the environmental UC problem. The biggest challenge lies in obtaining consistent values from the sparse information given by the manufacturers for the identified units - usually only the rated power and efficiency are advised. Then major contributions of this work are:

- The cross disciplinary bridge between CCGT modeling and power dispatch strategies.

- The development of a systematic comprehensive CCGT model whose granularity is adapted to with the MILP formulation for UC problems.

- The $\mathrm{CO}_{2}$ start-up costs are not explicitly entered as parameters in the UC. Instead the off design performance is estimated below the minimum operating point and start-up phases are modeled.

The rest of the paper is organized as follows. Section II describes the model used to represent the considered units and the obtained results. The general equations are given and a particular attention is attached to the optimal procedures that allow estimating both nominal and off design performance. Then Section III introduces the environmental unit commitment performed while considering four distinct power plants. Some constraints equations are presented. The conclusions are then presented in Section IV. 
Fig. 1. Simplified diagram of a typical CCGT unit

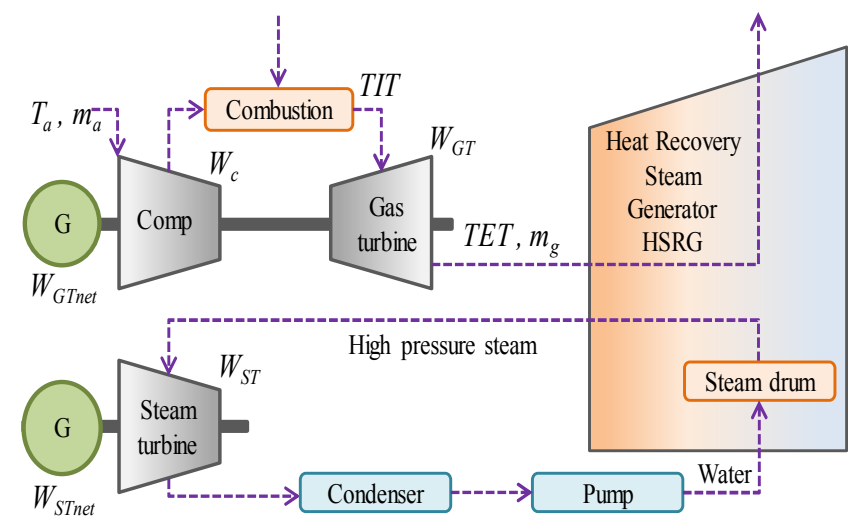

\section{CCGT MODELING}

\section{A. Fundamentals and Identified Generation on Site}

Fig. 1 shows a simplified diagram of a CCGT. The operation of such a unit lies on the combination of two thermodynamic cycles. In the top Brayton cycle the input air mass low $m_{a}$ (in $\mathrm{kg} / \mathrm{s}$ ) at ambient conditions is compressed with a ratio $r_{c}$ before entering the combustion chamber of the gas turbine. The combustion with a fuel mass flow $m_{f}$ (in $\mathrm{kg} / \mathrm{s}$ ) allows the flue gases to reach the turbine inlet temperature TIT (in ${ }^{\mathrm{O}} \mathrm{C}$ ) before their expansion that produces a work $W_{G T}$ (in MW). A nomenclature of all the considered parameters is given on Table I. Among those both $r_{c}$ and TIT have the greatest influence on the GT performances with highest values around 40 and $1600{ }^{\circ} \mathrm{C}$ respectively for the most efficient systems [7]. The main limitations come from the maximum stress that the different materials can endure under operating constraints. In the bottom Rankine cycle, the hot gases at the turbine exhaust temperature TET (in ${ }^{\mathrm{O}} \mathrm{C}$ ) are used in a heat recovery steam generator (HSRG) to produced superheated steam at high temperature for a steam turbine. Note that typical architectures for HSRG display up to three different pressure systems with corresponding low, intermediate and high pressure steam turbines. Thus the combine cycle (CC) units allow exploiting the available heat in the exhausts gas of heavy duty and enhancing the power generation efficiency from $40 \%\left(\eta_{G T}\right)$ to $60 \%(\eta C C)[7]$.

Such units represent more than half the installed power generation capacity in Singapore and up to $95 \%$ of mix in term of electricity generation [1]. Field data and manufacturers websites identify five types of units on Jurong Island with the characteristics advised in Table II and distributed among four power plant as follows:

- Keppel Merlimau (KPL): Units $\mathrm{A}_{1}$ and $\mathrm{A}_{2}$, Units $\mathrm{B}_{1}$ and $\mathrm{B}_{2}$.

- Pacific Light Power (PLP): Units $\mathrm{C}_{1}$ and $\mathrm{C}_{2}$.

- SembCorp Cogen (SMB): Unit $\mathrm{A}_{1}$, Units $\mathrm{D}_{1}$ and $\mathrm{D}_{2}$.

- YLT Seraya (SRY): Units $\mathrm{C}_{1}$ and $\mathrm{C}_{2}$, Units $\mathrm{E}_{1}$ and $\mathrm{E}_{2}$.
TABLE I. NOMENCLATURE FOR THE CCGT MODEL

\begin{tabular}{|c|c|c|}
\hline$T_{a}$ & ambient temperature & ${ }^{\mathrm{O}} \mathrm{C}$ \\
\hline$r_{c}$ & compression ratio & - \\
\hline$n_{c}$ & compressor isentropic efficiency & - \\
\hline$n_{m}$ & mechanical efficiency & - \\
\hline$m_{a}$ & air mass flow & $\mathrm{kg} / \mathrm{s}$ \\
\hline$\gamma_{c}$ & air specific heat ratio in compression & - \\
\hline$W_{c}$ & compressor consumed power & MW \\
\hline$C_{p a}$ & specific heat of air & $\mathrm{kJ} / \mathrm{kg} / \mathrm{K}$ \\
\hline$n_{c c}$ & combustion chamber efficiency & - \\
\hline$\lambda$ & air/fuel ratio in combustion chamber & - \\
\hline$L H V$ & fuel lower heat value & $\mathrm{kJ} / \mathrm{kg}$ \\
\hline$T I T$ & turbine inlet temperature & ${ }^{\mathrm{O}} \mathrm{C}$ \\
\hline$m_{f}$ & fuel mass flow & $\mathrm{kg} / \mathrm{s}$ \\
\hline$m_{g}$ & flue gas mass flow & $\mathrm{kg} / \mathrm{s}$ \\
\hline$C_{p g}$ & specific heat of flue gas & $\mathrm{kJ} / \mathrm{kg} / \mathrm{K}$ \\
\hline$\gamma_{e}$ & air specific heat ratio gas turbine expansion & - \\
\hline$n_{g t}$ & gas turbine isentropic efficiency & - \\
\hline$T E T$ & turbine exhaust temperature & ${ }^{\mathrm{O}} \mathrm{C}$ \\
\hline$W_{\text {GTnet }}$ & gas turbine net output power & MW \\
\hline$Q_{G T}$ & heat supplied to the gas turbine & $\mathrm{kJ} / \mathrm{s}$ \\
\hline$n_{\text {gen }}$ & electrical generator efficiency & - \\
\hline$\eta_{G T}$ & gas turbine efficiency & - \\
\hline$Q_{A V}$ & available heat in the flue gas & $\mathrm{kJ} / \mathrm{s}$ \\
\hline$W_{\text {STnet }}$ & steam net output power & MW \\
\hline$W_{C C}$ & combined cycle net output power & MW \\
\hline$\eta_{C C}$ & combined cycle efficiency & - \\
\hline$S C E$ & specific carbon emission & $\mathrm{kg} / \mathrm{MWh}$ \\
\hline . des & subscript for design values & - \\
\hline
\end{tabular}

TABLE II. IDENTIFIED UNITS ON SITE

\begin{tabular}{lccccc}
\hline & Unit A & Unit B & Unit C & Unit D & Unit E \\
\hline$W_{\text {GTnet }}(\mathrm{MW})$ & 240.0 & 165.0 & 260.0 & 256.0 & 292.0 \\
$W_{\text {STnet }}(\mathrm{MW})$ & 160.0 & 85.0 & 140.0 & 152.0 & 115.0 \\
$W_{C C}(\mathrm{MW})$ & 400.0 & 250.0 & 400.0 & 408.0 & 407.0 \\
$T E T\left({ }^{\mathrm{O}} \mathrm{C}\right)$ & 630.0 & 505.0 & 580.0 & 596.0 & 580.0 \\
$\eta_{G T}(\%)$ & 37.0 & 36.4, & 38.5 & 37.8 & 40.7 \\
$\eta_{C C}(\%)$ & 32.0 & 53.1 & 58.8 & 56.7 & 59.0 \\
\hline
\end{tabular}

\section{B. Model Equations}

This subsection describes the steady state equations commonly used in the literature for the modeling of CCGT units. Firstly the temperature at the output of the compressor $T_{c, \text { out }}\left(\right.$ in ${ }^{\mathrm{O}} \mathrm{C}$ ) is computed as well as the corresponding work $W_{c}$ (in MW) as in (1) and (2) [10]. Note that $C_{p a}($ in $\mathrm{kJ} / \mathrm{kg} / \mathrm{K})$ is estimated at the average temperature between Ta and $T_{c, \text { out }}$ and referring to the tables for air properties.

$T_{c, \text { out }}=T_{a} \times\left(1+\frac{r_{c}^{\frac{\gamma_{c}-1}{\gamma_{c}}}-1}{n_{c}}\right)$
$W_{c}=\frac{m_{a} \times C_{p a} \times\left(T_{c, \text { out }}-T_{a}\right)}{1000 \times n_{m}}$

A complete combustion of pure methane is considered (3). Similarly to [9] the combustion equations has to be solved in order to estimate the fuel mass flow $m_{f}$ (in $\mathrm{kg} / \mathrm{s}$ ) required to reach the turbine inlet temperature. The heat capacity of the flue gas $C_{p g}(\mathrm{in} \mathrm{kJ} / \mathrm{kg} / \mathrm{K})$ is also obtained after solving a second 
order polynomial equation with the molar air fuel ratio $\lambda$ (4). $C_{p g}$ is computed with the molar quantities and specific heat of each component in the flues gas and using the corresponding property tables. $M_{a}, M_{f}, n_{a}$, and $n f$ denote the molar masses and quantities of fuel and air.

$$
\begin{aligned}
& \mathrm{CH}_{4}+2 \cdot \lambda \cdot\left(\mathrm{O}_{2}+3,76 \cdot \mathrm{N}_{2}\right) \rightarrow \ldots . \\
& \ldots . \mathrm{CO}_{2}+2 \mathrm{H}_{2} \mathrm{O}+2 \cdot \lambda \cdot 3,76 \cdot \mathrm{N}_{2}+(2 \cdot \lambda-2) \cdot \mathrm{O}_{2} \\
& \left\{\begin{array}{l}
m_{a} \times\left(C_{p g} \times T I T-C_{p a} \times T_{c, \text { out }}\right)=m_{f} \times\left(L H V \times n_{c c}-C_{p g} \times T I T\right) \\
\frac{m_{f}}{m_{a}}=\frac{\mathrm{M}_{f} \times n_{f}}{\mathrm{M}_{a} \times n_{a}}=\frac{\mathrm{M}_{f}}{\mathrm{M}_{a} \times \lambda} \\
C_{p g}=\frac{n_{C O_{2}} \cdot C_{p C O_{2}}+n_{H_{2} O} \cdot C_{p H_{2} O}+n_{N_{2}} \cdot C_{p N_{2}}+n_{O_{2}} \cdot C_{p_{O_{2}}}}{n_{C O_{2}}+n_{\mathrm{H}_{2} O}+n_{N_{2}}+n_{O_{2}}}=\ldots \\
C_{p C O_{2}}+2 \cdot C_{p H_{2} O}-2 \cdot C_{p_{O_{2}}} \cdot C_{p N_{2}}+\left(2 \times 3.76 \cdot C_{p N_{2}}+2 \cdot C_{p C O}\right) \cdot \lambda \\
1+(2 \times 3.76+2) \cdot \lambda
\end{array}\right.
\end{aligned}
$$

The computation of the GT output work $W_{\text {GTnet }}$ (in MW) requires the estimation of the turbine exhaust temperature TET (in ${ }^{\mathrm{O}} \mathrm{C}$ ) as shown in (5) and (6). The overall CC net ouput power is then obtained following (7). Note that the HSRG is not fully modeled here with the superheater, the economizer, the deaerator and condenser equations. In this work the steam turbine work output $W_{\text {STnet }}$, once the heat is extracted from the exhaust gas, is given as an input fixed parameter at design conditions (input parameter $W_{\text {STnet }}$ ). The specific $\mathrm{CO}_{2}$ emissions $S C E$ (in $\mathrm{kg} / \mathrm{MWh}$ ) consider the $\mathrm{CO}_{2}$ molar mass $\mathrm{M}_{\mathrm{CO} 2}$ and the fuel molar quantity $n_{f}(9)$.

$$
\begin{aligned}
& T E T=T I T \times\left(1-n_{g t} \times\left(1-\frac{1}{r_{c}^{\frac{\gamma_{e}-1}{\gamma_{e}}}}\right)\right) \\
& W_{G T n e t}=\frac{m_{g} \times C_{p g} \times(T I T-T E T)}{1000} \times n_{m} \times n_{g e n}-W_{c} \\
& W_{C C}=W_{G T n e t}+W_{\text {STnet }} \\
& S C E=\frac{n_{f} \times M_{C O_{2}} \times 3600}{1000 \times W_{C C}}
\end{aligned}
$$

The heat supplied to the gas turbine $Q_{G T}$ (in MW) [8] is used to compute the thermal efficiencies for the GT and the overall CC unit as follows:

$$
\begin{aligned}
& Q_{G T}=\frac{m_{g} \times C_{p g} \times\left(T I T-T_{c, \text { out }}\right)}{1000} \\
& \eta_{G T}=\frac{W_{G T_{\text {net }}} \text { and } \eta_{C C}=\frac{W_{C C}}{Q_{G T}}}{Q_{G T}}
\end{aligned}
$$

Fig. 2. Inputs/Outputs of the CCGT model

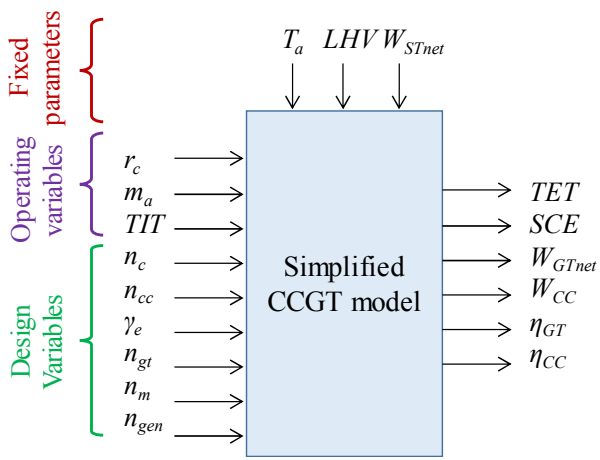

\section{Off-Design Operations}

The previous equations describe the behavior of a typical CCGT at the design operating point. Such a representation with a more detailed model of the HSRG is used in [8] to perform the optimal sizing of a CCGT unit with regard to capital and operating costs. In power system studies the units never operate at the nominal point all along the considered time horizon [9]. It is obvious with the totality of a variable load fed by a finite numbers of units as it is the case in the system modeled here. Thus a particular attention has to be paid to the off-design operating points and constraints. Especially the objective is to estimate the carbon emissions on the whole operating range of the units. The first off-design constraint refers to the fulfillment of the schoked conditions of the gas turbine with a constant swallowing capacity (10). Here the compression ratio is used instead of the compressor output pressure [9].

$$
\frac{m_{a} \times \sqrt{T I T}}{r_{c}}=\frac{m_{a, d e s} \times \sqrt{T I T_{d e s}}}{r_{c, \text { des }}} \leftrightarrow G_{s h}=G_{s h}^{D}
$$

Reference [11] establishes semi empirical equations for the behavior of the steam turbine under off-design conditions. The output power has to be corrected regarding the deviations of the flue gas mass flow $m_{g}$ (in $\mathrm{kg} / \mathrm{s}$ ) and $T E T$ from their design values while considering $\eta_{c}$, the Carnot cycle efficiency (9). $W_{S T n e t}$ then tends to decrease in the same time than $Q_{A V}$ the heat available in the GT exhaust gas ((10) and (11)). Note that a more accurate representation of the off-design performances should take the deviations of the isometric efficiencies for the compressor and the gas turbine into account. It is not considered here and constant values are used.

$\eta_{c}=1-\frac{T_{a}}{T E T}$

$\frac{Q_{A V}}{Q_{A V, \text { des }}}=\left(\frac{T E T}{T E T_{\text {des }}}\right)^{2}\left(\frac{m_{g}}{m_{g, d e s}}\right)$

$W_{\text {STnet }}=\frac{W_{\text {STnet }, \text { des }}}{n_{m} \times n_{\text {gen }}} \times\left(\frac{\eta_{c}}{\eta_{c, \text { des }}}\right) \times \ldots$

$\ldots\left(-0.32063+1.64575 \times \frac{Q_{A V}}{Q_{A V, \text { des }}}-\times 0.32872 \frac{Q_{A V}{ }^{2}}{Q_{A V, d e s}{ }^{2}}\right)$ 


\section{Optimization for Design and Part Load Operating Points}

The model developed for CCGT units displays the architecture shown on Fig. 2 with fixed parameters $L H V=48685 \mathrm{~kJ} / \mathrm{kg}$ and $T_{a}=30{ }^{\circ} \mathrm{C}$. The next step consists in calibrating the model. The objective is to optimize all the inputs (i.e. both design and operating variables) in order to minimize the error between the outputs and the values advised by the manufacturers (noted with the superscript.$^{D}$ ). The design objective $o d j{ }^{D}$ is then expressed as the sum of the errors regarding the values for $T E T, W_{G T n e t}$ and $\eta_{G T}$. (12). The CC output power and efficiency are implicitly fit as the ST net power is entered as a fixed parameter here. For the off-design operations only the three operating variables are optimized. The unit operation consists in the control of the inlet guide vane of the compressor. The operation is based on IVG control up to $30 \%$ air flow reduction with constant TET followed by a maximum air flow control [9]. The operating controls are then optimized considering their design values as upper bounds $\left(m_{a}>0.7 \times m_{\text {ades }}\right)$. The off-design objective odj $O D$ aims at ensuring the shocked conditions, maintaining TET at the highest possible value while minimizing the error with the part load CC output power $W_{C C}^{O D}$.

$$
\begin{aligned}
& o b j=\frac{\left(W_{G T n e t}-W_{G T n e t}^{D}\right)^{2}}{W_{G T n e t}^{D}{ }^{2}}+\frac{\left(T E T-T E T^{D}\right)^{2}}{T E T^{D^{2}}}+\frac{\left(\eta_{G T}-\eta_{G T}^{D}\right)^{2}}{\eta_{G T}^{D^{2}}} \\
& o b j^{O D}=\frac{\left(W_{C C}-W_{C C}^{O D}\right)^{2}}{W_{C C}^{O D^{2}}}+\frac{\left(T E T-T E T^{D}\right)^{2}}{T E T^{D^{2}}}+\frac{\left(G_{s h}-G_{s h}^{D}\right)^{2}}{G_{s h}^{D^{2}}}
\end{aligned}
$$

The two optimization problems described above are solved using the Sequential Quadratic Programming embedded in the Matlab Optimization Toolbox. For every design and every part load point of each unit the problems are run with a hundred starting points randomly taken within the bounds for the variables. Note that the off-design operation points are considered between $30 \%$ and $100 \%$ off the nominal load with a step of $5 \%$.

\section{E. Obtained Results}

Design results shows good performances. The errors for the output CC power and TET are below $0.1 \%$ while e the maximum registered deviation for the efficiencies is only $0.6 \%$. The results also display the specific $\mathrm{CO}_{2}$ emission estimated for the different units ranging from $391 \mathrm{~kg} / \mathrm{MWh}$ to $457 \mathrm{~kg} / \mathrm{MWh}$ The observed values are close as it is expected for units with similar performances in terms of efficiency. Those SCE values are consistent with the ones found in the literature for Singapore field data [1]. Fig. 3 shows the results obtained while running the off-design model for Unit A. Especially the operating variables variations are consistent with the considered control strategy [12]. TET remain constant while the air mass flow and the compressions ratio decrease to reach load points below $100 \%$ of the nominal load (Fig. 3a). Once the lower bound for $m_{a}$ is met (0.7), TET starts decreasing allowing the unit to work a lower output powers.
Fig. 3. Performances of Unit $\mathrm{A}-a$ ) Operating veraibles $-b$ ) efficiencies
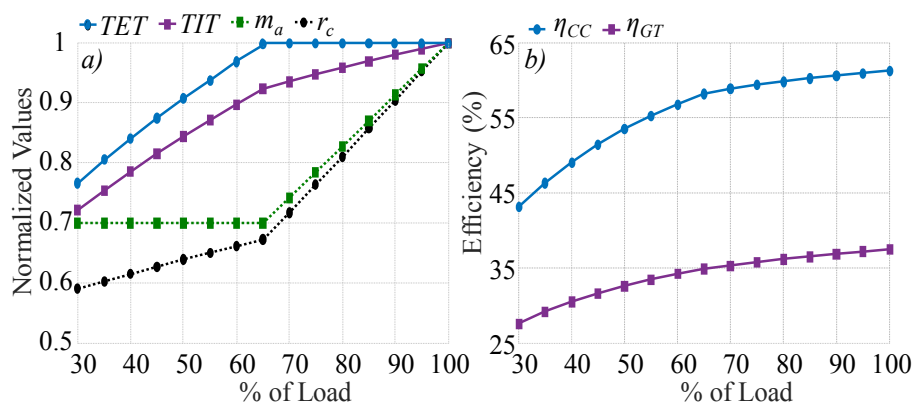

Fig. 4. Units performances - a) $S C E-b) \mathrm{CO}_{2}$ emissions
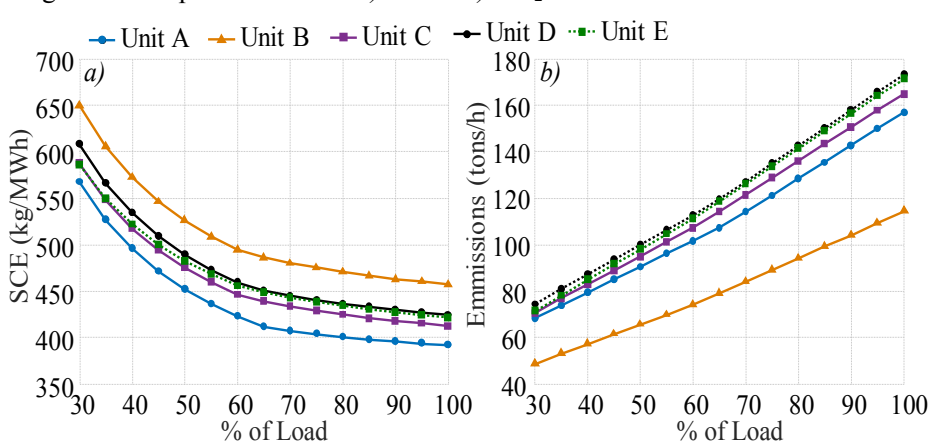

Consequently, the CC efficiency drops around $20 \%$ for the unit works at $30 \%$ of the nominal load. The same observation can be made concerning the $S C E$ which increase significantly when the output power decreases (Fig. 4a). Plotting the SCE allows ranking the units from the dirtiest (Unit B) to the cleanest (Unit A). Multiplying the specific emissions by the corresponding output power for the units allows estimating the net emissions in tons. Note that the emission for Unit B are significantly lower as the rated power is less important than for the other technologies (250 MW Vs $400 \mathrm{MW})$. Fig. $4 \mathrm{~b}$ highlights the fact that the emissions $E_{i}$ for for the $i^{\text {th }}$ unit can be expressed with a linear formulation (14). That will be used as an input parameter for the objective function of the UC problem in the next part. Table III gives the values for the different $a_{i}, b_{i}$ obtained with regression coefficients greater than 0.99 .

$$
E_{i}\left(W_{C C}\right)=a_{i} \times \frac{W_{C C}}{W_{C C, \text { des }}}+b_{i}
$$

\section{ENVIRONMENTAL UC}

\section{A. CCGT Units Operations}

Typical constraints for thermal units in power dispatch proecedures refer to the ramping limitation and minimum up/down times [2]. More accurate approaches for thermal units consist in introducing the different phase for the operations as well as discriminating the start-up types [20].

TABLE III.

LINEAR COEFFICIENTS FOR CO2 EMISSIONS

\begin{tabular}{lccccc}
\hline & Unit A & Unit B & Unit C & Unit D & Unit E \\
\hline$a_{i}$ (in tons) & 126.56 & 94.00 & 135.16 & 141.51 & 143.34 \\
$b_{i}$ (in tons) & 27.67 & 19.13 & 28.00 & 29.59 & 26.94 \\
\hline
\end{tabular}


Fig. 5. CCGT unit operation

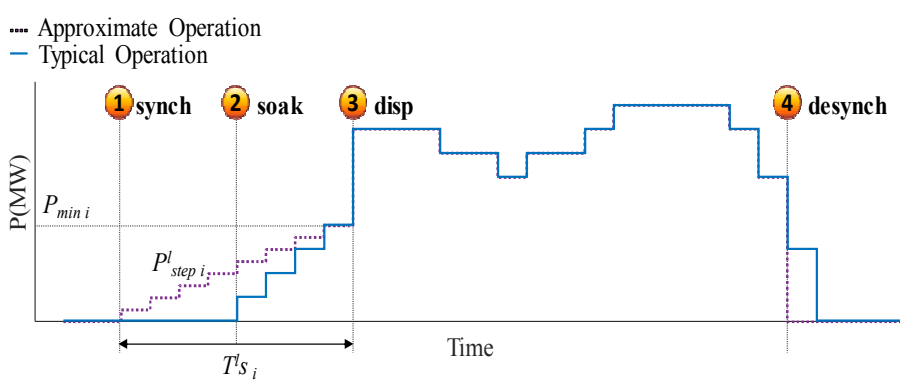

When a CCGT unit is committed it first enters in a synchronization phase where the turbine shaft reaches the synchronization speed with the grid frequency (Fig. 5). Then a soak phase occurs with the output power that increases until the minimum operating point. The dispatchable phase then starts with the $i^{\text {th }}$ unit power flowing within the range $P_{\text {min, } i}$ and $P_{\max , i}$. When the unit is decommitted the power then returns to zero during the desynchronization phase. In this work both synchronization and soak phase are combined as the only available duration is the total start time (dotted line model in Fig. 5). The start-up time tends to increase with the prior reservation time during which the unit is turned off. Three start-up types $l=$ hot, warm, cold are then commonly considered with associated duration $T s_{i}^{l}$.

TABLE IV. OPERARTING PARAMETERS

\begin{tabular}{|c|c|c|c|c|c|}
\hline & Unit A & Unit B & Unit C & Unit D & Unit E \\
\hline $\operatorname{Ramp}(\mathrm{MW} / \mathrm{min})$ & 50 & 30 & 10 & 22 & 10 \\
\hline$T s^{h o t}{ }_{i}(\min )$ & 30 & 60 & 60 & 30 & 60 \\
\hline$T s^{\text {warm }_{i}}(\min )$ & 90 & 120 & 120 & 90 & 120 \\
\hline$P_{\min , i}(\mathrm{MW})$ & 80 & 75 & 120 & 142 & 122 \\
\hline$P_{\max , i}(\mathrm{MW})$ & 400 & 250 & 400 & 408 & 407 \\
\hline
\end{tabular}

Table IV gives the operating variables for the considered units. Note that with a daily UC cold start (after more than $120 \mathrm{~h} \mathrm{off})$ is not considered. The load is considered with a $30 \mathrm{~min}$ discretization $(\Delta t=30 \mathrm{~min})$ based on the data for the whole year 2016 [1]. With such a time step the ramp constraints do not need to be considered. It appears that the studied units can fully operates on their whole range during only one increment of time. Also the duration of the desynchronization phase is neglected as they are usually lower than the start-up phase time.

\section{B. Problem Formulation}

In the present study the MILP is considered for the UC formulation. The problem is formulated in MATLAB using YALMIP and is solved using CPLEX 12.7.1. As already mentioned the objective of the UC here is to meet the load with the minimum amount of $\mathrm{CO}_{2}$. The objective function is expressed as in (15) with the output power of the $i^{\text {th }}$ unit at time $t P_{i, t}$ and the on/off status $u_{i, t}$. A nomenclature for some of the symbols used in the UC is given in Table $\mathrm{V}$.

obj: Min $\sum_{t \in T} \sum_{i \in U}\left(a_{i} \times \frac{P_{i, t}}{P_{\max , i}}+b_{i} \times u_{i, t}\right) \times \Delta t$
Note that the start-up costs (in tons of $\mathrm{CO}_{2}$ ) don't appear in the function as it is commonly done in such studies [5]. That information is not available for the considered units. Thus the models previously developed are used to estimate the start-up emissions while extending the off-design operations a lower values of the delivered power. With a non null duration for the start-up phase the corresponding $\mathrm{CO}_{2}$ cost is computed when considering the output power trajectories from 0 to $P_{\min , i}$ (Fig. 5). Consequently, and as expected, warm start-ups will be costlier with a longer duration. Then the first set of constraints attached to the UC problem describes the start up type selection based on the reservation times bounds $T^{d}{ }_{l}$ and $T_{l}{ }_{l}$ prior the start up. $T^{u}{ }_{l}=8 \mathrm{~h}$ for hot start and $T_{l}{ }_{l}=24 \mathrm{~h}$ for warm start. $T^{d}{ }_{l}=0 \mathrm{~h}$ for hot start and $T^{d}{ }_{l}=8 \mathrm{~h}$ for warm start. The constraints in (16) allows selecting the start-up type depending on the prior reservation time and Eq. (17) ensures that only one type is selected among $S$ [12]. The unit immediately enters in start-up phase when $v_{i, t}$ is set to 1 (18) while Eq. (19) ensures that only the appropriate start phase is considered. The power delivered by the unit $i$ in start-up phase $l$ at time $t$ is computed by multiplying the step power $P_{\text {step }, i}$ by the duration of the phase before $t(20)$. The reader can refer to [12] for a compete formulation of the UC involving logical constraints for the units operations.

$$
\begin{aligned}
& v_{i, t}^{l} \leq \sum_{t-T_{l}^{u}+1}^{t-T_{l}^{d}} w_{i, t} \\
& v_{i, t}=\sum_{l \in S} v_{i, t}^{l} \\
& u s_{i, t}^{l}=\sum_{t-T s_{l}+1}^{t} v_{i, t}^{l} \\
& u s_{i, t}=\sum_{l \in S} u s_{i, t}^{l} \\
& P s_{i, t}=\sum_{t-T s_{l}+1}^{t} \sum_{l \in S} u s_{i, t}^{l} \times P_{\text {step } i}^{l} \text { and } P s_{i, t} \leq P_{\text {max }, i} \times u s_{i, t}
\end{aligned}
$$

TABLE V. NOMENCLATURE FOR UC PROBLEM

\begin{tabular}{ll}
\hline$u_{i, t}$ & unit $i$ committed at time $t$ \\
$u s_{i, t}$ & unit $i$ in start phase at time $t$ \\
$u s_{i, t}^{l}$ & unit $i$ in start phase typle $l$ at time $t$ \\
$v_{i, t}$ & unit $i$ started at time $t$ \\
$v_{i, t}^{l}$ & unit $i$ started type $l$ at time $t$ \\
$w_{i, t}$ & unit $i$ shut down at time $t$ \\
$P_{i, t}$ & power generated by unit $i$ at time $t$ \\
$P s_{i, t}$ & power generated by unit $i$ in start phase at time $t$ \\
$a_{i,} b_{i}$ & coefficients for the $\mathrm{CO}_{2}$ emissions of unit $i$ \\
$P_{\text {min,i }} / P_{\max , i}$ & min/max power of unit $i$ in dispatchable phase \\
$T_{s_{l}}$ & start up type $l$ duration \\
$P_{s t e p}^{l} i$ & power increment of unit of during start up type $l$ \\
$T^{d}{ }_{l}, T_{l} l$ & bounds for start up type $l$ intervals \\
$T, U, S$ & set of time steps, units and start-up types
\end{tabular}


Fig. 6. UC without start-up phases $-a) \mathrm{KPL}-$ b) PLP - c) SMB - d) SRY
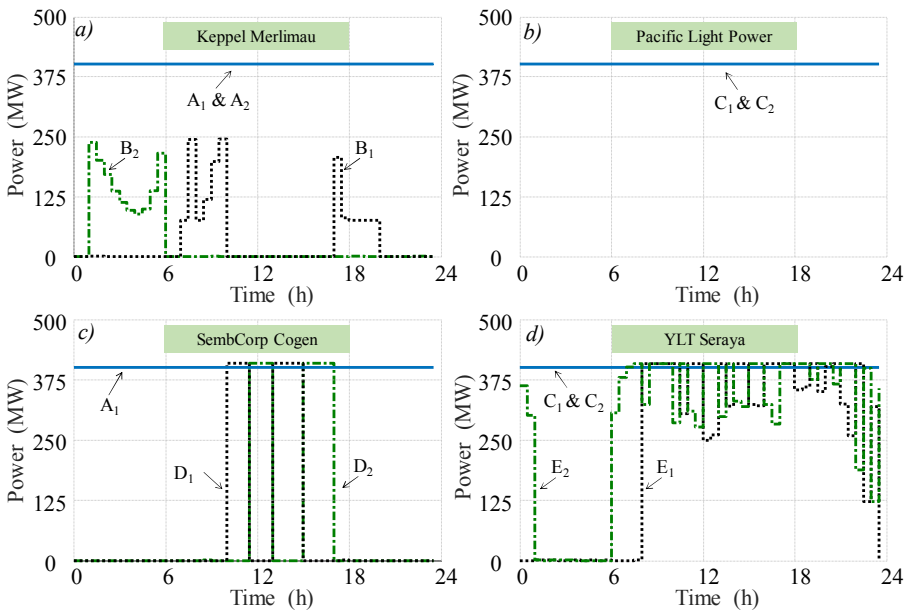

Fig. 7. UC with start-up phases $-a) \mathrm{KPL}-$ b) $\mathrm{PLP}-c$ ) $\mathrm{SMB}-d$ ) SRY
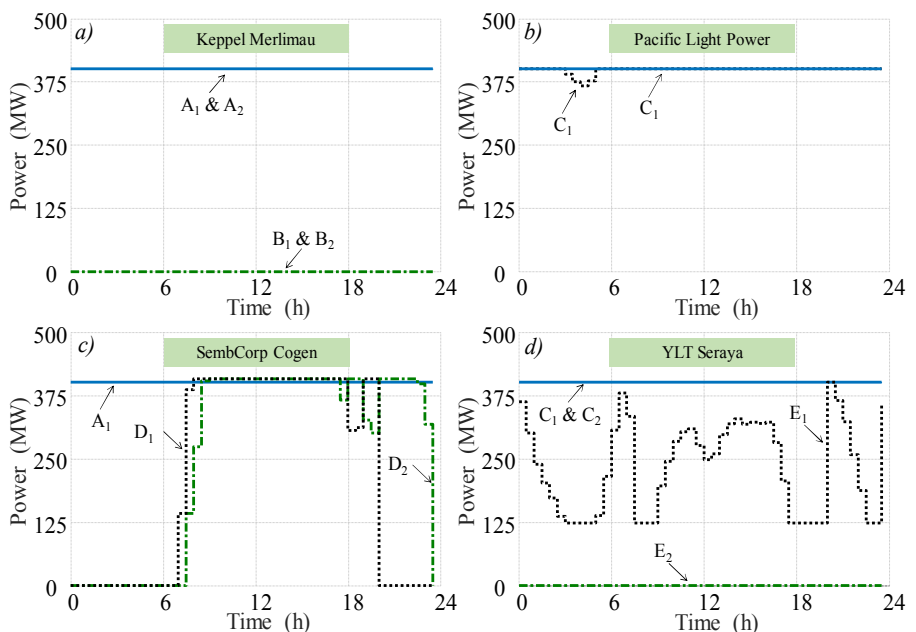

\section{A. Obtained Results}

At first the simulation is performed without considering the constraints for the start-up phases. The obtained confirms that the cleanest units (A and $\mathrm{C}$ ) are run in priority all along the day while the dirtiest (D) are much less solicited (Fig. 7). Without considering the start-up phases some units displays multiple starts and stops during the simulated day which is unrealistic and would dramatically increases the costs of generation (Fig. 7a). Introducing the start-up constrains solves the problem by avoiding multiple commitments within the same day for the dirtiest units as shown on Fig. 8. It can be noticed that the base load is still fed by the cleanest units while the peak load is meet with the commitment of units D in PLP and $E_{1}$ in SRY (Fig. 8b and Fig. 8d). Note that the dirtiest units B in KPL are not used at all. The simulation allows computing the grid emission factor $(G E F)$ which represent the amount of $\mathrm{CO}_{2}$ per $\mathrm{kWh}$ generated. The obtained values is $0.406 \mathrm{~kg} / \mathrm{kWh}$. That is consistent with the recorded $G E F$ of $0.431 \mathrm{~kg} / \mathrm{kWh}$ for the year 2016 in Singapore which also considers grid losses as well as well $5 \%$ of the electricity mixed coming from oil steam plants [1].

\section{CONCLUSIONS}

The CCGT model described in this paper aims at estimating the $\mathrm{CO}_{2}$ emission coefficients that are used in an environmental UC. Compared to conventional UC studies with $\mathrm{CO}_{2}$ costs taken from the literature, the methodology developed here allows the representation of specific units. Especially the start-up emission doesn't have to be guessed and is estimated by introducing the start-up phase with a specific duration. Despite the sparsity of the information available from unit manufacturers, the calibrated models display very good agreement with real data in terms of GEF. The global objective of the study is to model the power system management on Jurong Island in Singapore. Further work should focus on the grid modeling that would lead to additional operating constraints to be fulfilled in UC. Attention will have to be paid to the problem formulation in order to avoid prohibitive computational times. The aggregation of the units in the same plant could be investigated in order to reduce the number of variables and the attached solution time.

\section{REFERENCES}

[1] Energy Market Authority. "Singapore Energy Statistics". 2016 (web: www.ema.gov.sg).

[2] K. Van den Bergh, K. Bruninx, E. Delarue, W. D'haeseleer, “A MixedInteger Linear Formulation of the Unit Commitment Problem”, KU Leuven, TME working paper, 2014

[3] L. Deng, B. F. Hobbs, P. Renson, "What is the Cost of Negative Bidding by Wind? A Unit Commitment Analysis of Cost and Emissions", IEEE Transaction on Power Systems, Vol 30, No 4, pp 1805-18014, 2015.

[4] D. Yamashita, T. Niimura, R. Yokoyama, M. Marmiroli, "Trade-off Analysis of $\mathrm{CO} 2$ versus Cost by Multi-objective Unit Commitment", Power and Energy Society General Meeting, Providence, USA, 2010.

[5] S. Krishnamurthy, R. Tzoneva, "Impact of price penalty factors on the solution of the combined economic emission dispatch problem using cubic criterion functions", Power and Energy Society General Meeting, San Diego, USA, 2012.

[6] D. W. Gong, Y. Zhang, C. Qi, "Environmental/economic power dispatch using a hybrid multi-objective optimization algorithm", Electrical Power and Energy Systems, Vol 32, pp 607-614, 2010.

[7] M. P. Boyce. "Handbook for cogeneration and combined cycle power plants". ASME Press. $2^{\text {nd }}$ Edition. 2010.

[8] Y. Zhu, H. C. Frey, "Simplified Performance Model of Gas Turbine Combined Cycle Systems", Journal of Energy Engineering ASCE, pp 8290, 2007.

[9] T.S. Kim. "Comparative analysis on the part load performance of combined cycle plants considering design performance and power control strategy”. Energy. Vol 29. pp 71-85. 2004.

[10] T. K. Ibrahim. M. M. Rahman. "Thermal Impact of Operating Conditions on the Performance of a Combined Cycle Gas Turbine". Journal of Applied Research and Technology. pp 567-577. 2012.

[11] G. Zhang. J. Zheng. A. Xie. Y.Yang. W. Liu. "Thermodynamic performance simulation and concise formulas for triple-pressure reheat HRSG of gas-steam combined cycle under off-design condition". Energy Conversion and Management. Vol 121. pp 372-385. 2016.

[12] C. K. Simoglou, P. N. Biskas, A. G. Barkirtzis, "Optimal Self-Scheduling of a Thermal Producer in Short-Term Electricity Markets by MILP", IEEE Transactions on Power Sytems, Vol 25, No 4, pp 1965-1977, 2014. 